\title{
Sex Differences in Risk Factors Associated with Coronary Artery Disease: What Does Glycated Albumin Indicate?
}

\author{
Lin Sun ${ }^{1}$, Haitao Yuan ${ }^{1, *}$
}

\author{
${ }^{1}$ Department of Cardiovascular Disease, \\ Shandong Provincial Hospital affiliated \\ to Shandong University, Jinan, P.R. China

\section{*Correspondence} \\ yhtsdsl@163.com \\ (Haitao Yuan)
}

\begin{abstract}
Objective: To investigate gender differences in risk factors associated with coronary artery disease (CAD), and to explore the association between glycated albumin (GA) and CAD. Method: We recruited 350 adult patients, collected their clinical information and divided them into CAD and non-CAD groups, based on angiography results. Results: Patients with CAD showed significantly higher age related GA, fasting blood glucose, serum creatinine ( $\mathrm{SCr}$ ) and Gensini score. Multivariate Logistic regression analysis identified gender, age, superoxide dismutase(SOD) and GA as independent factors in CAD patients ( $p$ $<0.05$ ) and the mean GA level in females was higher than in males. Univariate linear regression analysis also showed that GA was not associated with male CAD patients. In females, SOD, low-density lipoprotein cholesterol (LDL-c), and GA were associated with a significant Gensini score $(\mathrm{p}<0.05)$. Finally, GA was capable of classifying CAD in women (AUC $>0.767 ; p<0.001$ ). Conclusion: GA is positively correlated with the severity of coronary artery obstruction in female patients presenting with CAD.
\end{abstract}

\section{Keywords}

Coronary artery disease, Angiography, Gensini score, Glycated albumin

\section{Introduction}

Diabetes mellitus (DM) has been demonstrated to be an independent risk factor for coronary artery disease [1]. It has been estimated that by the year 2045, there will be 693 million people living with diabetes worldwide, and many of these will develop vascular complications, including coronary artery disease (CAD) [2]. Hemoglobin A1c (HbA1c), is an important indicator of long-term glycemic control with the ability to reflect the cumulative glycemic history of the preceding 8-12 weeks. Thus, glycated HbAlc can indicate average blood glucose levels and this has been shown to be an independent risk factor for CAD. Glycated albumin (GA) however, is a glycemic product which reflects blood glucose levels from the previous 2-3 week period. And the levels of GA are more closely associated with CAD than glycated $\mathrm{HbA1c}$ [3]. It has further been reported that levels of serum GA are higher in female CAD patients than males, although this is yet to be confirmed [4].

In this study, 350 subjects who had undergone angiography were enrolled and their Gensini scores calculated based on their angiography results. The aim of this study was to investigate gender differences and associations between GA and stenosis severity in CAD patients.

\section{Materials and methods}

\subsection{Subjects}

We recruited 350 adult patients from the Department of Cardiology of Shandong Provincial Hospital from January 2013 to December 2019. The sample included 155 women (44.3\%) and 195 men (55.7\%). All subjects underwent coronary angiography and were divided into two groups. We placed patients who had $\geq 50 \%$ arterial obstruction into the $\mathrm{CAD}$ group, and the patients who had $\leq 50 \%$ arterial obstruction into the non-CAD group [5]. Exclusion criteria included patients with chronic heart failure, thyroid dysfunction, autoimmune disease, renal or liver dysfunction, or a malignant tumor. This study protocol was approved by the ethic committee of Shandong Provincial Hospital, Cheeloo College of Medicine, Shandong University. 
TA B L E 1. Stenosis score for different degree of coronary artery obstruction.

\begin{tabular}{lc} 
Coronary artery obstruction & Score A \\
$\leq 25 \%$ & 1 \\
\hline $26 \%-50 \%$ & 2 \\
$51 \%-75 \%$ & 4 \\
$76 \%-90 \%$ & 8 \\
$91 \%-99 \%$ & 16 \\
$100 \%$ & 32 \\
\hline
\end{tabular}

TA B LE 2. Lesion score for each site.

\begin{tabular}{lc} 
Lesion site & Score B \\
LM & 5 \\
LAD & Proximal: 2.5 ; Middle: 1.5 ; Distal: 1 \\
\hline LCX & Proximal: 2.5 ; Middle: 1 ; Distal: 1 \\
RCA & 1 \\
\hline Subbranch & 0.5 \\
\hline
\end{tabular}

LM: left main coronary artery; LAD: left anterior descending; LCX: left circumflex coronary; $R C A$ : right coronary artery.

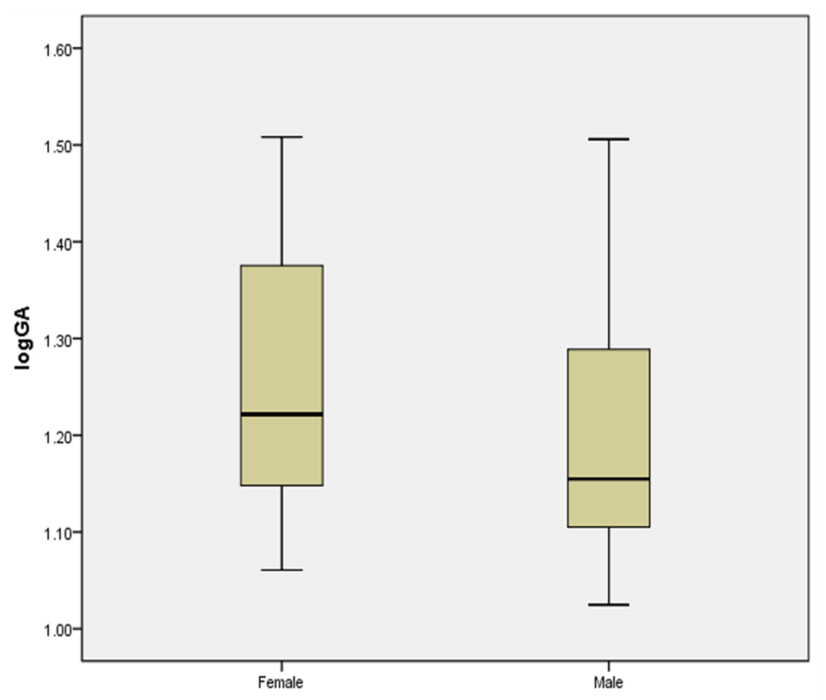

F I G U RE 1. Serum GA level in female and male.

\subsection{Clinical data collection}

At the point of hospitalization, we recorded general data, including sex, age, systolic blood pressure(SBP), diastolic blood pressure (DBP), complete disease history, personal history, any medication and results of physical examination for each subject. Patients with a current or former smoking habit for at least six months were defined as having a smoking history. Patients who had ever been diagnosed with DM were record as having a DM history. After 12 hours of fasting, we collected blood samples for biochemical measurements. The levels of SOD, hemocyanin (HCY), nonesterified fatty acid (NEFA), fasting blood glucose (FBG),

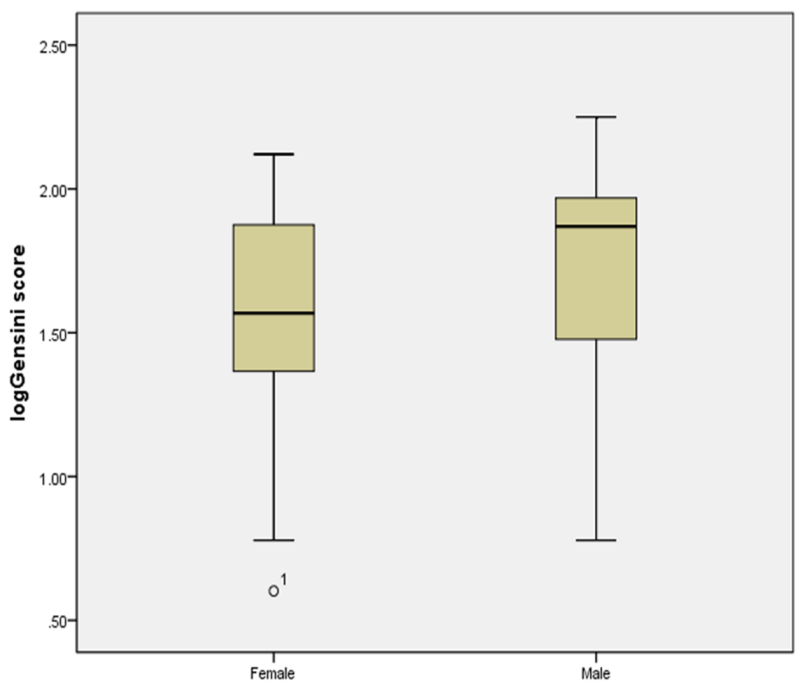

F I G U RE 2. Gensini score in female and male patients with CAD.

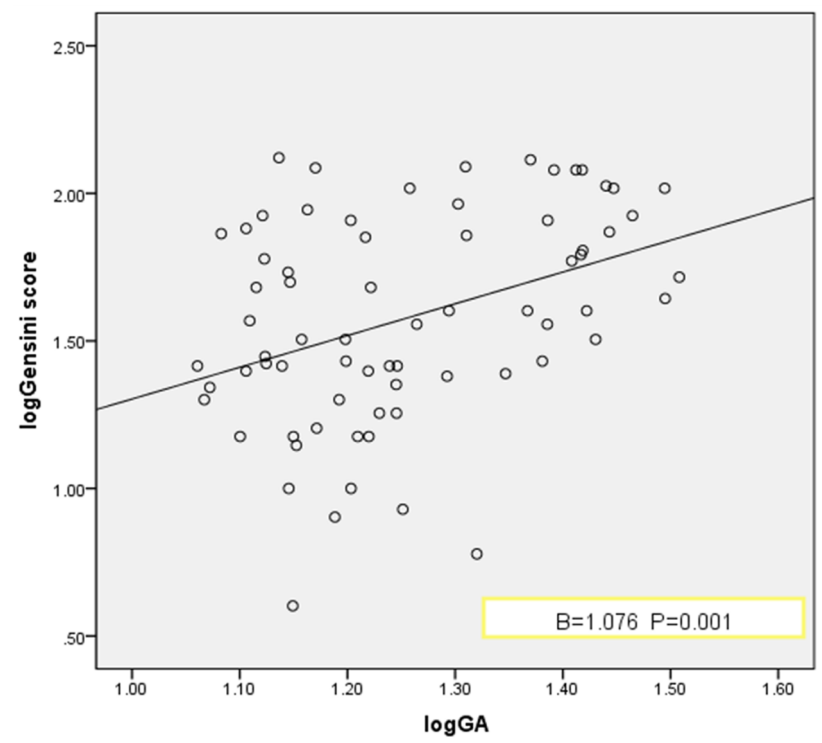

F I G URE 3. Correlation of the log gensini score with the Log GA in female CAD patients.

$\mathrm{SCr}$, uric acid, total cholesterol(TC), triglyceride (TG), high-density lipoprotein cholesterol (HDL-c), LDL-c, and GA were measured using standard assays conducted by the laboratory of Shandong Provincial Hospital. The estimated glomerular filtration rate (eGFR) was calculated using the CKD-EPI $_{S C r}$ formula: $\mathrm{GFR}=141 \times \min (\mathrm{SCr} / \kappa, 1)^{\alpha} \times$ $\max (\mathrm{SCr} / \kappa, 1)^{-1.209} \times 0.993^{\text {Age }} \times 1.018$ [if female] $\times$ 1.159 [if black] [6]. The degree of coronary artery stenosis was evaluated according to the Gensini scoring system of the American Heart Association [7], and a Gensini score was reached by multiplying score A and score B (Table 1, 2). 
T A B L E 3. Clinical characteristics of patients without and with CAD.

\begin{tabular}{|c|c|c|c|}
\hline & Patients without CAD & Patients with CAD & $\mathbf{p}$ \\
\hline & $(n=150)$ & $(n=200)$ & \\
\hline Age (years) & $59.03 \pm 9.11$ & $63.07 \pm 9.71$ & $<0.001$ \\
\hline $\operatorname{sex}$ & & & $<0.001$ \\
\hline Female $[\mathrm{n}(\%)]$ & $84(56 \%)$ & $71(35.5)$ & \\
\hline Male $[\mathrm{n}(\%)]$ & $66(44 \%)$ & $129(64.5)$ & \\
\hline $\mathrm{DM}[\mathrm{n}(\%)]$ & $22(14.7 \%)$ & $72(36 \%)$ & $<0.001$ \\
\hline $\operatorname{HBP}[\mathrm{n}(\%)]$ & $77(51.3 \%)$ & $131(65.5 \%)$ & 0.008 \\
\hline Smoking [n (\%)] & $45(30 \%)$ & $85(42.5 \%)$ & 0.017 \\
\hline Heart rate (beats/min) & $70.00(65.00,80.00)$ & $69.00(63.00,78.00)$ & 0.202 \\
\hline $\mathrm{SBP}(\mathrm{mmHg})$ & $131.79 \pm 19.30$ & $132.62 \pm 18.96$ & 0.687 \\
\hline DBP (mmHg) & $75.53 \pm 12.04$ & $75.38 \pm 10.79$ & 0.905 \\
\hline $\mathrm{SOD}(\mathrm{U} / \mathrm{mL})$ & $166.65(154.45,176.93)$ & $166.20(156.00,180.625)$ & 0.517 \\
\hline $\mathrm{HCY}(\mu \mathrm{mol} / \mathrm{L})$ & $12.00(10.35,14.73)$ & $12.75(11.20,15.95)$ & 0.013 \\
\hline NEFA (mmol/L) & $0.50(0.38 .0 .74)$ & $0.51(0.38,0.71)$ & 0.954 \\
\hline FBG (mmol/L) & $5.40(4.98,6.12)$ & $5.96(5.12,7.69)$ & $<0.001$ \\
\hline $\mathrm{SCr}(\mu \mathrm{mol} / \mathrm{L})$ & $62.43(55.00,71.25)$ & $67(57.25,77.75)$ & 0.003 \\
\hline eGFR & $96.50(89.75,102.25)$ & $95.00(86.00,104.00)$ & 0.558 \\
\hline Uric $\operatorname{acid}(\mu \mathrm{mol} / \mathrm{L})$ & $327.93 \pm 82.56$ & $331.60 \pm 96.78$ & 0.71 \\
\hline $\mathrm{TG}(\mathrm{mmol} / \mathrm{L})$ & $1.42(1.10,1.96)$ & $1.47(1.10,1.96)$ & 0.599 \\
\hline $\mathrm{TC}(\mathrm{mmol} / \mathrm{L})$ & $4.46(3.83,5.23)$ & $4.07(3.55,5.06)$ & 0.006 \\
\hline HDL-c (mmol/L) & $1.20(1.00,1.42)$ & $1.16(0.99,1.36)$ & 0.134 \\
\hline LDL-c (mmol/L) & $2.70(2.17,3.22)$ & $2.49(1.99,3.18)$ & 0.083 \\
\hline GA $(\%)$ & $14.11(13.09,15.53)$ & $14.88(13.15,20.23)$ & 0.004 \\
\hline Gensini score & $2.00(0.00,5.00)$ & $56.00(25.00,89.13)$ & $<0.001$ \\
\hline \multicolumn{4}{|l|}{ Medications } \\
\hline Anti-platelet drugs [n (\%)] & $143(95.3 \%)$ & $200(100 \%)$ & 0.002 \\
\hline Statins $[\mathrm{n}(\%)]$ & $137(91.3 \%)$ & $195(97.5 \%)$ & 0.01 \\
\hline Beta-blockers [n (\%)] & $102(68 \%)$ & $158(79 \%)$ & 0.02 \\
\hline ACEIs or ARBs [n (\%)] & $41(27.3 \%)$ & $97(48.5 \%)$ & $<0.001$ \\
\hline CCBs $[\mathrm{n}(\%)]$ & $34(22.7 \%)$ & $54(27 \%)$ & 0.355 \\
\hline Diuretics $[\mathrm{n}(\%)]$ & $13(8.7 \%)$ & $30(15 \%)$ & 0.074 \\
\hline OADs [n (\%)] & $19(12.7 \%)$ & $72(36.0 \%)$ & $<0.001$ \\
\hline
\end{tabular}

\subsection{Statistical analyses}

The non-parametric Kolmogorov-Smirnov test was conducted to assess the normality of the distribution among continuous variables. Normally distributed variables were expressed as mean \pm standard deviation and analyzed by an independent-sample $t$-test. Variables not satisfying a normal distribution were presented as median values and analyzed by the Mann-Whitney U-test. Categorical variables were presented as numbers (percentages) and underwent a Chi-Square test. Parameters which were not normally distributed were log transformed before regression analysis. Box plots were performed to examine GA and Gensini score by sex. The relationship between Gensini score, gender and CAD was examined using univariate linear regression analysis, followed by multivariate liner regression analysis for independent risk factors derived from the univariate liner regression analysis. A partial correlation was carried out between GA, Gensini score, and DM. Simple linear regression analysis was performed between GA and Gensini score in females, and a receiver operating characteristic (ROC) curve was drawn to evaluate the predicted cutoff value for GA. A probability (p) value $<0.05$ was considered to have a significant statistical difference. All data analyses were performed with SPSS (version 21.0). 
TA B L E 4. Clinical characteristics of female and male patients with CAD.

\begin{tabular}{|c|c|c|c|}
\hline & Female Patients & Male Patients & $\mathbf{p}$ \\
\hline & $(\mathrm{n}=71)$ & $(n=129)$ & \\
\hline Age (years) & $65.45 \pm 8.16$ & $61.76 \pm 10.26$ & 0.01 \\
\hline $\mathrm{DM}[\mathrm{n}(\%)]$ & $33(46.5 \%)$ & $39(30.2 \%)$ & 0.022 \\
\hline $\operatorname{HBP}[\mathrm{n}(\%)]$ & $48(67.6 \%)$ & $83(64.3 \%)$ & 0.642 \\
\hline Smoking [n (\%)] & $5(7.0 \%)$ & $80(62.0 \%)$ & $<0.001$ \\
\hline Heart rate(beats/min) & $68.00(60.00,70.00)$ & $70.00(64.00,79.00)$ & 0.238 \\
\hline SBP (mmHg) & $134.48 \pm 18.45$ & $131.6 \pm 19.23$ & 0.305 \\
\hline DBP (mmHg) & $73.70 \pm 11.56$ & $76.30 \pm 10.28$ & 0.103 \\
\hline $\mathrm{SOD}(\mathrm{U} / \mathrm{mL})$ & $164.60(155.30,179.00)$ & $166.70(157.05,181.50)$ & 0.385 \\
\hline $\mathrm{HCY}(\mu \mathrm{mol} / \mathrm{L})$ & $11.90(9.80,13.80)$ & $13.9(11.55,16.90)$ & $<0.001$ \\
\hline NEFA (mmol/L) & $0.53(0.41,0.78)$ & $0.50(0.37,0.65)$ & 0.066 \\
\hline $\mathrm{FBG}(\mathrm{mmol} / \mathrm{L})$ & $6.52(5.24,7.87)$ & $5.68(5.06,7.23)$ & 0.053 \\
\hline $\mathrm{SCr}(\mu \mathrm{mol} / \mathrm{L})$ & $56.36(51.00,64.00)$ & $73.00(65.00,83.00)$ & $<0.001$ \\
\hline eGFR & $93.00(85.00,99.00)$ & $98.00(87.00,107.50)$ & 0.01 \\
\hline Uric acid $(\mu \mathrm{mol} / \mathrm{L})$ & $293.30 \pm 86.07$ & $352.67 \pm 96.17$ & $<0.001$ \\
\hline $\mathrm{TG}(\mathrm{mmol} / \mathrm{L})$ & $1.48(1.14,1.96)$ & $1.45(1.08,1.95)$ & 0.617 \\
\hline $\mathrm{TC}(\mathrm{mmol} / \mathrm{L})$ & $4.25(3.66,5.11)$ & $3.96(3.44,4.86)$ & 0.062 \\
\hline HDL-c (mmol/L) & $1.21(1.04,1.47)$ & $1.10(0.97,1.32)$ & 0.002 \\
\hline LDL-c (mmol/L) & $2.53(1.97,3.24)$ & $2.47(2.05,3.08)$ & 0.538 \\
\hline GA $(\%)$ & $16.66(14.02,24.04)$ & $14.28(12.73,19.44)$ & 0.001 \\
\hline Gensini score & $37.00(22.50,76.00)$ & $74.00(29.50,93.50)$ & 0.006 \\
\hline \multicolumn{4}{|l|}{ Medications } \\
\hline Anti-platelet drugs [n (\%)] & $71(100 \%)$ & $129(100 \%)$ & $a^{*}$ \\
\hline Statins $[\mathrm{n}(\%)]$ & $70(98.6 \%)$ & $129(100 \%)$ & 0.463 \\
\hline Beta receptor blockers $[\mathrm{n}(\%)]$ & $54(76.1 \%)$ & $104(80.6 \%)$ & 0.448 \\
\hline ACEIs/ARBs [n (\%)] & $37(52.1 \%)$ & $60(46.5 \%)$ & 0.448 \\
\hline CCBs $[n(\%)]$ & $20(28.2 \%)$ & $34(26.4 \%)$ & 0.782 \\
\hline Diuretics [n (\%)] & $11(15.5 \%)$ & $20(15.5 \%)$ & 0.885 \\
\hline OADs [n (\%)] & $35(49.3 \%)$ & $37(28.7 \%)$ & 0.004 \\
\hline
\end{tabular}

$a^{*}$, the variable is a constant.

\section{Results}

\subsection{Characteristics of all subjects}

Table 3 indicates the characteristics of all included patients. In the CAD group, there were more subjects with a history of DM $(\mathrm{p}<0.001)$, high blood pressure (HBP) $(\mathrm{p}=$ $0.008)$, smoking $(p=0.017)$, increased administration of anti-platelet drugs $(\mathrm{p}=0.002)$, statins $(\mathrm{p}=0.010)$, betablockers $(p=0.020)$, angiotensin-converting enzyme inhibitors (ACEIs), angiotensin II receptor blocker (ARBs) (p $<0.001)$, and oral antidiabetic agents (OADs) $(p=0.001)$ when compared to the non-CAD group. Male patients were in the majority among the CAD group, whereas female subjects made up the majority within the non-CAD group. Patients in the CAD group displayed increased age levels ( $p<0.001)$, HCY $(p=0.013)$, FBG $(p<0.001), S C r(p$
$=0.003)$, GA $(p=0.004)$, Gensini score $(p<0.001)$ but lower levels of total cholesterol $(p=0.006)$. There were no significant differences seen between the two groups in heart rate, systolic blood pressure, DBP, superoxide dismutase, NEFA, eGFR, uric acid, triglyceride, LDL-c, HDL-c, ratio of administration of calcium channel blockers (CCBs) or diuretics.

\subsection{Clinical characteristics of male and female patients in the CAD and non-CAD groups}

Data provided in Table 4 indicates that female patients were of higher age than the males. The males also had higher HCY, SCr, eGFR, uric acid, and Gensini score $(p=0.006)$, when compared to the females, but had lower levels of 
TA B L E 5. Clinical characteristics of female and male patients without CAD.

\begin{tabular}{|c|c|c|c|}
\hline & Female Patients & Male Patients & $\mathbf{p}$ \\
\hline & $(n=84)$ & $(n=66)$ & \\
\hline Age (years) & $61.06 \pm 7.59$ & $56.44 \pm 10.22$ & 0.003 \\
\hline $\mathrm{DM}[\mathrm{n}(\%)]$ & $15(17.9 \%)$ & $7(10.6 \%)$ & 0.251 \\
\hline $\mathrm{HBP}[\mathrm{n}(\%)]$ & $42(50.0 \%)$ & $35(53.0 \%)$ & 0.744 \\
\hline Smoking $[\mathrm{n}(\%)]$ & $4(4.8 \%)$ & $41(62.1 \%)$ & $<0.001$ \\
\hline Heart rate(beats/min) & $69.50(64.25,78.00)$ & $72.00(65.75,80.00)$ & 0.296 \\
\hline $\mathrm{SBP}(\mathrm{mmHg})$ & $131.94 \pm 19.04$ & $131.59 \pm 19.78$ & 0.913 \\
\hline DBP (mmHg) & $73.44 \pm 12.14$ & $78.18 \pm 11.45$ & 0.016 \\
\hline $\mathrm{SOD}(\mathrm{U} / \mathrm{mL})$ & $164.95(150.48,175.78)$ & $168.10(157.53,181.55))$ & 0.092 \\
\hline $\mathrm{HCY}(\mu \mathrm{mol} / \mathrm{L})$ & $11.30(9.25,14.15)$ & $13.00(11.40,15.85)$ & 0.001 \\
\hline NEFA (mmol/L) & $0.55(0.41,0.80)$ & $0.48(0.31,0.61)$ & 0.01 \\
\hline FBG (mmol/L) & $5.46(5.02,6.36)$ & $5.36(4.97,5.90)$ & 0.528 \\
\hline $\mathrm{SCr}(\mu \mathrm{mol} / \mathrm{L})$ & $56.00(49.00,62.00)$ & $72.00(66.00,79.00)$ & $<0.001$ \\
\hline eGFR & $97.50(91.00,102.00)$ & $95.50(88.00,104.00)$ & 0.42 \\
\hline Uric acid $(\mu \mathrm{mol} / \mathrm{L})$ & $303.67 \pm 78.45$ & $358.82 \pm 77.76$ & $<0.001$ \\
\hline $\mathrm{TG}(\mathrm{mmol} / \mathrm{L})$ & $1.37(1.11,1.90)$ & $1.47(1.08,2.00)$ & 0.531 \\
\hline $\mathrm{TC}(\mathrm{mmol} / \mathrm{L})$ & $4.39(3.84,5.17)$ & $3.82(4.43,5.01)$ & 0.278 \\
\hline HDL-c (mmol/L) & $1.24(1.09,1.44)$ & $1.13(0.95,1.35)$ & 0.003 \\
\hline LDL-c (mmol/L) & $2.73(2.21,3.17)$ & $2.58(2.15,3.22)$ & 0.617 \\
\hline GA $(\%)$ & $13.30(12.65,15.12)$ & $13.89(12.69,14.99)$ & 0.034 \\
\hline Gensini score & $2.00(0.00,4.88)$ & $2.00(0.00,5.00)$ & 0.665 \\
\hline \multicolumn{4}{|l|}{ Medications } \\
\hline Anti-platelet drugs [n (\%)] & $80(95.2 \%)$ & $63(95.5 \%)$ & 1 \\
\hline Statins $[\mathrm{n}(\%)]$ & $79(94.0 \%)$ & $58(87.9 \%)$ & 0.244 \\
\hline Beta receptor blockers [n (\%)] & $59(70.2 \%)$ & $43(65.2 \%)$ & 0.597 \\
\hline ACEIs/ARBs [n (\%)] & $21(25.0 \%)$ & $20(30.3 \%)$ & 0.58 \\
\hline CCBs $[\mathrm{n}(\%)]$ & $19(22.6 \%)$ & $15(22.7 \%)$ & 1 \\
\hline Diuretics $[\mathrm{n}(\%)]$ & $7(8.3 \%)$ & $6(9.1 \%)$ & 1 \\
\hline OADs [n (\%)] & $12(14.3 \%)$ & $7(10.6 \%)$ & 0.623 \\
\hline
\end{tabular}

HDL-c and GA $(\mathrm{p}=0.001)$. There were more smokers and less DM patients in the male group. The female subjects in the CAD group taking OADs accounted for more than those in the male group. The mean GA levels in females was found to be higher than in the males, whereas the Gensini score levels were higher in males than in females (Fig. 1,2). Clinical characteristics was also presented for the non-CAD group, comparing male and female characteristics and, as Table 5 shows, the female subjects were of higher age ( $p$ $=0.003)$ and had higher NEFA $(\mathrm{p}=0.01)$ and HDL-c $(\mathrm{p}$ $=0.003$ ) levels when compared to the males. In contrast, females had lower DBP $(\mathrm{p}=0.016), \operatorname{HCY}(\mathrm{p}=0.001), \mathrm{SCr}$ $(p<0.001)$, Uric acid $(p<0.001)$ and GA $(p=0.034)$ levels when compared to the male patients. Finally, there were more smokers present in the in male group $(\mathrm{p}<0.001)$.

\subsection{The effect of gender on clinical factors in the CAD groups}

Univariate logistical regression analysis revealed that there were significant differences between male and female CAD subjects in terms of smoking ( $p<0.001)$, the level of HCY $(p=0.009)$, NEFA $(p=0.011), \operatorname{SCr}(p<0.001)$, eGFR $(p$ $=0.002)$, uric acid $(\mathrm{p}=0.045), \mathrm{TG}(\mathrm{p}=0.003), \mathrm{GA}(\mathrm{p}=$ $0.018)$ and Gensini score $(p=0.009)$. (Table 6)

\subsection{Correlation between clinical risk factors and Gensini score among male patients with CAD}

Univariate linear regression analysis detailed the relevant risk factors for $\mathrm{CAD}$ in male patients, including age, heart rate, GA, and administration of statins or Beta-blockers (Table 7). Multivariate linear regression analysis further 
TA B L E 6. Univariate logistic analyses for sex (male) in CAD patients.

\begin{tabular}{|lcc}
\multicolumn{1}{c}{ Variable } & & Univariate Analysis \\
\hline Age (years) & B & p \\
\hline DM & 4.408 & 0.061 \\
\hline HBP & NS & 0.045 \\
\hline Smoking & 4.707 & 0.164 \\
\hline Log HR & NS & 0.001 \\
\hline SBP (mmHg) & NS & 0.17 \\
\hline DBP (mmHg) & NS & 0.069 \\
\hline Log SOD & NS & 0.62 \\
\hline Log HCY & 10.87 & 0.009 \\
\hline Log NEFA & -4.481 & 0.011 \\
\hline Log FBG & NS & 0.418 \\
\hline Log SCr & 18.11 & $<0.001$ \\
\hline Log eGFR & 23.744 & 0.002 \\
\hline Uric acid $(\mu m o l / L)$ & 0.013 & 0.045 \\
\hline Log TG & -8.719 & 0.003 \\
\hline Log TC & NS & 0.774 \\
\hline Log HDL & NS & 0.073 \\
\hline Log LDL & NS & 0.886 \\
\hline Log GA & -13.735 & 0.018 \\
\hline Log Gensini score & 3.326 & 0.009 \\
\hline Medications & & \\
\hline Anti-platelet drugs & $\mathrm{a} *$ & $\mathrm{~b}^{*}$ \\
\hline Statins & NS & 0.462 \\
\hline Beta-blockers & NS & 0.232 \\
\hline ACEIs or ARBs & NS & 0.535 \\
\hline CCBs & NS & 0.727 \\
\hline Diuretics & NS & 0.459 \\
\hline OADs & NS & 0.128 \\
\hline * $b^{*}$, & \\
\hline
\end{tabular}

$a^{*}, b^{*}$, the variable is a constant; NS, not significant.

identified that age and high heart rates were independent risk factors for coronary obstruction, and administration of statins may alleviate arterial stenosis, while GA was not related to coronary obstruction.

\subsection{Correlation between clinical risk factors and Gensini score among female patients with CAD}

Univariate linear regression analysis revealed a positive correlation between a history of DM, fasting blood glucose, GA, and coronary stenosis in the female CAD group (Table 8). Multivariate linear regression analysis identified that high levels of GA were an independent risk factor for coronary obstruction $(\mathrm{p}=0.002)$. Partial correlation analy-

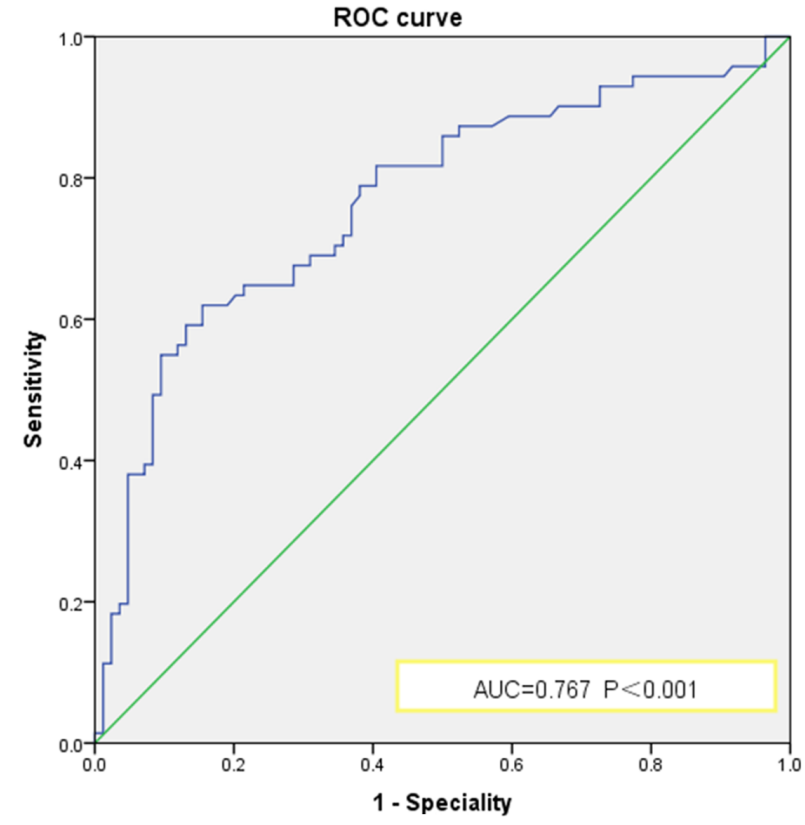

FIGURE 4. A receiver operating characteristic (ROC) curve of GA in CAD patients.

The area under ROC (receiver operating characteristic) curve $>0.767 ; p<0.001$.

sis verified a positive correlation between GA and Gensini score in relation to a previous history of DM (Table 9). Fig. 3 shows the simple linear regression analysis results for the correlation between GA and Gensini score in females (B $=1.076, \mathrm{p}=0.001)$. The ROC curve shows that GA had a significant ability to discriminate between the non-CAD and CAD groups (Fig. 4, AUC $=0.767, \mathrm{p}<0.001$ ). We calculated that the optimal predictive value is $\mathrm{GA}>15.77$ (Youden's index $=1.465$ ).

\section{Discussion}

Currently, the gold standard for monitoring blood glucose levels is blood HbAlc concentration and this has been proved to be an independent marker for cardiovascular disease risk [8]. However, HbAlc can be influenced by the presence of drugs, ethnicity, and other factors. Recently, GA has been demonstrated to be a novel marker for glucose levels within a previous 2-3 week period, and studies have also found that GA is associated with carotid arterial atherosclerosis, and serum albumin can function as an antioxidant [9]. Furthermore, exposure to hyperglycemia leads to a decrease in antioxidant activity and the progression of atherosclerosis. It has also been shown that the level of serum GA may predict an increased progression in the thickness of the arterial intima-media and therefore, may represent a pro-atherosclerotic protein. CAD is also a common complication of diabetes, history of DM is an independent risk factor for $\mathrm{CAD}$, and studies have found that GA is closely related to its development. It has also reported that the level of GA is significantly higher in women than in men among patients with $\mathrm{CAD}$ [9]. However, whether 
TA B L E 7. Univariate and multivariate linear regression analyses for the gensini score in male patients with CAD.

\begin{tabular}{|c|c|c|c|c|}
\hline \multirow[t]{3}{*}{ Variable } & \multicolumn{2}{|c|}{ Univariate Analysis } & \multirow{2}{*}{\multicolumn{2}{|c|}{$\begin{array}{c}\text { Multivariate Analysis } \\
\text { Model 1, r }=0.399\end{array}$}} \\
\hline & \multirow[b]{2}{*}{ B } & \multirow[b]{2}{*}{$\mathbf{p}$} & & \\
\hline & & & B & $\mathbf{p}$ \\
\hline Age (years) & 0.007 & 0.021 & 0.007 & 0.02 \\
\hline $\mathrm{DM}$ & NS & 0.69 & Not Selected & \\
\hline HBP & NS & 0.225 & Not Selected & \\
\hline Smoking & NS & 0.653 & Not Selected & \\
\hline Log HR & 0.992 & 0.032 & 0.893 & 0.047 \\
\hline SBP (mmHg) & NS & 0.956 & Not Selected & \\
\hline DBP (mmHg) & NS & 0.646 & Not Selected & \\
\hline Log SOD & NS & 0.318 & Not Selected & \\
\hline Log HCY & NS & 0.236 & Not Selected & \\
\hline Log NEFA & NS & 0.616 & Not Selected & \\
\hline Log FBG & NS & 0.286 & Not Selected & \\
\hline $\log \mathrm{SCr}$ & NS & 0.247 & Not Selected & \\
\hline Log eGFR & NS & 0.657 & Not Selected & \\
\hline Uric acid $(\mu \mathrm{mol} / \mathrm{L})$ & NS & 0.842 & Not Selected & \\
\hline $\log \mathrm{TG}$ & NS & 0.059 & Not Selected & \\
\hline $\log \mathrm{TC}$ & NS & 0.353 & Not Selected & \\
\hline Log HDL & NS & 0.054 & Not Selected & \\
\hline Log LDL & NS & 0.194 & Not Selected & \\
\hline Log GA & 0.586 & 0.02 & $b^{*}$ & \\
\hline \multicolumn{5}{|l|}{ Medications } \\
\hline Anti-platelet drugs & $a^{*}$ & & Not Selected & \\
\hline Statins & -0.425 & 0.015 & -0.375 & 0.027 \\
\hline Beta-blockers & 0.156 & 0.041 & $b^{*}$ & \\
\hline ACEIs or ARBs & NS & 0.217 & Not Selected & \\
\hline $\mathrm{CCBs}$ & NS & 0.756 & Not Selected & \\
\hline Diuretics & 0.173 & 0.043 & $b^{*}$ & \\
\hline OADs & NS & 0.651 & Not Selected & \\
\hline
\end{tabular}

$a^{*}$, the variable is a constant; $b^{*}$, the variables didn't enter the multivariate liner regression, NS, not significant.

GA can be interpreted as an independent risk factor and a predictive marker remains unclear; however, in this study, we confirmed that GA is positively correlated with the severity of coronary artery stenosis in female patients.

We observed that serum GA levels in the CAD group were significantly higher than those in the non-CAD group, which are consistent with results of previous studies. Compared to male patients, GA levels in females were higher. It is noted that multiple linear regression analysis was performed for male and female CAD patients, but only female patients had a positive correlation between GA and Gensini score. Considering the potential enhancement of diabetes, we further carried out partial correlation analysis and found that GA was positively correlated with Gensini score among female CAD patients. In conclusion, we found that GA is an independent risk factor for coronary stenosis in female patients with CAD.

We constructed a ROC curve to determine the discriminative ability of GA in women. According to the area under the ROC curve, an increase in GA levels had a prognostic role on CAD. When serum GA is higher than 15.7 , it is indicative of an increased probability of developing CAD.

We recognize that there are some limitations to this study. First, the effect of age and hormone balance on GA was not included in our data analysis. Estrogen has a role in the stabilization of plaques, increasing insulin sensitivity, and regulating blood lipid and blood glucose metabolism, thereby exerting cardiovascular protection [10]. Studies also have shown that serum estrogen levels in postmenopausal women decrease significantly [11]. 
TA B L E 8. Univariate and stepwise multivariate linear regression analyses for the gensini score in female patients with CAD.

\begin{tabular}{|c|c|c|c|c|}
\hline \multirow[t]{3}{*}{ Variable } & \multicolumn{2}{|c|}{ Univariate Analysis } & & \multirow{2}{*}{$\begin{array}{r}\text { Multivariate Analysis } \\
\text { Model 1, } r=0.525\end{array}$} \\
\hline & & & & \\
\hline & B & $\mathbf{p}$ & B & $\mathbf{p}$ \\
\hline Age (years) & NS & 0.558 & Not Selected & \\
\hline DM & 0.174 & 0.04 & $b^{*}$ & \\
\hline HBP & NS & 0.235 & Not Selected & \\
\hline Smoking & NS & 0.337 & Not Selected & \\
\hline Log HR & NS & 0.467 & Not Selected & \\
\hline $\mathrm{SBP}(\mathrm{mmHg})$ & NS & 0.842 & Not Selected & \\
\hline DBP (mmHg) & NS & 0.77 & Not Selected & \\
\hline Log SOD & -2.377 & 0.008 & -2.037 & 0.016 \\
\hline Log HCY & NS & 0.079 & Not Selected & \\
\hline Log NEFA & NS & 0.241 & Not Selected & \\
\hline Log FBG & 0.72 & 0.041 & $b^{*}$ & \\
\hline Log SCr & NS & 0.915 & Not Selected & \\
\hline Log eGFR & NS & 0.773 & Not Selected & \\
\hline Uric acid $(\mu \mathrm{mol} / \mathrm{L})$ & NS & 0.656 & Not Selected & \\
\hline $\log \mathrm{TG}$ & NS & 0.834 & Not Selected & \\
\hline $\log \mathrm{TC}$ & NS & 0.521 & Not Selected & \\
\hline Log HDL & NS & 0.169 & Not Selected & \\
\hline Log LDL & NS & 0.191 & Not Selected & \\
\hline $\log$ GA & 1.076 & 0.001 & 0.975 & 0.002 \\
\hline \multicolumn{5}{|l|}{ Medications } \\
\hline Anti-platelet drugs & $a^{*}$ & & Not Selected & \\
\hline Statins & NS & 0.954 & Not Selected & \\
\hline Beta-blockers & NS & 0.102 & Not Selected & \\
\hline ACEIs or ARBs & NS & 0.058 & Not Selected & \\
\hline $\mathrm{CCBs}$ & NS & 0.056 & Not Selected & \\
\hline Diuretics & NS & 0.206 & Not Selected & \\
\hline OADs & 0.21 & 0.012 & $b^{*}$ & \\
\hline
\end{tabular}

$a^{*}$, the variable is a constant, $b^{*}$, the variables didn't enter the multivariate liner regression; NS, not significant.

TA B L E 9. Partial correlation between GA and gensini score by DM.

\begin{tabular}{|ccccc|} 
Control & & & Log GA & Log Gensini score \\
\hline DM & Log GA & Correlation & 1 & 0.318 \\
& & p. & & 0.007 \\
& & df & 0 & 68 \\
& Log Gensini score & Correlation & 0.318 & 1 \\
& & p. & 0.007 & \\
& & df & 68 & 0 \\
\hline
\end{tabular}

Consequently, $\beta$ cell apoptosis and insulin resistance are more marked in women than in men of the same age $[10,11]$. Thus, GA levels may be affected by women's age. We did not record the menstrual status of female CAD patients, but the average age of the females in the CAD patient group was 65 years of age, therefore, most 
women in this group were likely postmenopausal. Thus, this study may stengthen the correlation between GA and Gensini score. Second, this study is a cross-sectional study and cannot determine the causal relationship between GA and atherosclerosis - a topic that is clearly worthy of future study.

In conclusion, our findings show there are differences between $\mathrm{CAD}$ patients based on gender. In women, the increase in serum GA level is positively correlated with obstruction of CAD. Furthermore, diabetes and serum GA are independent risk factors for coronary atherosclerosis. Finally, our findings suggest that there is a predictive potential for differences in GA levels to identify CAD in women.

\section{ACKNOWLEDGMENTS}

Thank numerous individuals participated in this study.

\section{CONFLICT OF INTEREST}

We declare that we do not have any commercial or associative interest that represents a conflict of interest in connection with the work submitted.

\section{REFERENCES}

[1] Yahagi K, Kolodgie FD, Lutter C, et al. Pathology of Human Coronary and Carotid Artery Atherosclerosis and Vascular Calcification in Diabetes Mellitus. Arterioscler Thromb Vasc Biol. 2017;37:191-204.

[2] N.H. Cho, J.E. Shaw, S. Karuranga, et al. Global estimates of diabetes prevalence for 2017 and projections for 2045. IDF Diabetes Atlas. 2018;138:271-81.

[3] Ma X, Hu X, Zhou J, et al. Glycated albumin is more closely correlated with coronary artery disease than 1,5-anhydroglucitol and glycated hemoglobin A1c. Cardiovasc Diabetol. 2015;14:16.

[4] Selvin E, Rawlings AM, Lutsey PL, et al. Fructosamine and Glycated Albumin and the Risk of Cardiovascular Outcomes and Death. Circulation. 2015;132:269-77.

[5] Ryan TJ, Faxon DP, Gunnar RM, et al. Guidelines for percutaneous transluminal coronary angioplasty. A report of the American College of Cardiology/American Heart Association Task Force on Assessment of Diagnostic and Therapeutic Cardiovascular Procedures (Subcommittee on Percutaneous Transluminal Coronary Angioplasty). J Am Coll Cardiol. 1988;12:529-45.

[6] Ma YC, Zuo L, Chen JH, et al. Modified glomerular filtration rate estimating equation for Chinese patients with chronic kidney disease. J Am Soc Nephrol. 2006;17:2937-44.

[7] Alan B, Akpolat V, Aktan A, et al. Relationship between osteopenic syndrome and severity of coronary artery disease detected with coronary angiography and Gensini score in men. Clin Interv Aging. 2016;11:377-82.

[8] Vouillarmet J, Marsot C, Maucort-Boulch D, et al. Vascular Events and Carotid Atherosclerosis: A 5-Year Prospective Cohort Study in Patients with Type 2 Diabetes and a Contemporary Cardiovascular Prevention Treatment. J Diabetes Res. 2019:9059761.

[9] Song SO, Kim K J, Lee BW, et al. Serum glycated albumin predicts the progression of carotid arterial atherosclerosis. Atherosclerosis. 2012;225:450-5

[10] Lee AS, Chen WY, Chan HC, et al. Gender disparity in LDL-induced cardiovascular damage and the protective role of estrogens against electronegative LDL. Cardiovasc Diabetol. 2014;13:64.

[11] Khalil RA. Estrogen, vascular estrogen receptor and hormone therapy in postmenopausal vascular disease. Biochem Pharmacol. 2013;86:1627-42.

How to cite this article: Lin Sun, Haitao Yuan. Sex Differences in Risk Factors Associated with Coronary Artery Disease: What Does Glycated Albumin Indicate? Signa Vitae. 2020;16(1):137145. doi:10.22514/sv.2020.16.0018. 